\title{
Il devait conter une histoire
}

Jean-Marie Privat

\section{(2) OpenEdition}

Journals

Édition électronique

URL : https://journals.openedition.org/clo/1736

DOI : $10.4000 /$ clo. 1736

ISSN : 2266-1816

Éditeur

INALCO

\section{Édition imprimée}

Date de publication : 2 janvier 2012

ISBN : 978-2-85831-212-2

ISSN : 0396-891X

\section{Référence électronique}

Jean-Marie Privat, « II devait conter une histoire », Cahiers de littérature orale [En ligne], 72 | 2012, mis en ligne le 29 avril 2015, consulté le 01 juillet 2021. URL : http://journals.openedition.org/clo/1736 ; DOI : https://doi.org/10.4000/clo.1736

Ce document a été généré automatiquement le 1 juillet 2021.

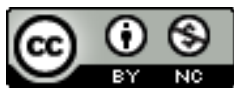

Cahiers de littérature orale est mis à disposition selon les termes de la Licence Creative Commons Attribution - Pas d'Utilisation Commerciale 4.0 International. 


\title{
Il devait conter une histoire
}

\author{
Jean-Marie Privat
}

1 «Il devait, sur l'ordre du baron, conter une histoire pour indemniser les déshérités ». C'est sur cette impérieuse exigence que se clôt la Bécasse, le récit-cadre du célèbre recueil de Maupassant intitulé lui-même contes de la bécasse (Maupassant, 1974, 666-668) ${ }^{1}$. Qui est ce baron qui ordonne de conter? C'est le vieux baron des Ravots, un ancien chasseur désormais paralysé des jambes; il ne trouve plus divertissement que dans les histoires, racontées par ses invités à l'issue des dîners qui clôturent les parties de chasse à la campagne qu'il organise chaque année, à l'automne (Weber, 1983, 590-597)2. Le conteur est désigné, soir après soir, par le bec d'une tête de bécasse fixée sur un bouchon que l'on fait tourner sur un goulot de bouteille :

2 Celui des invités que désignait, en s'arrêtant, le long bec pointu devenait maître de toutes les têtes, régal exquis qui faisait loucher ses voisins (...). L'élu du hasard croquait le crâne suiffé (...) en poussant des exclamations de plaisir (...). Puis, quand il avait achevé le dernier, il devait, sur l'ordre du baron, conter une histoire pour indemniser les déshérités.

3 Voici quelques-uns de ces récits 3 .

\section{Les délégations de parole}

La Bécasse se présente donc comme un prologue narratif qui institue une même et fictive situation de contage oral pour chacun des seize récits rassemblés par Maupassant lorsqu'il constitua l'édition de son recueil ${ }^{4}$. La critique a fait observer à juste titre que les liens entre cette sorte de pré-texte et les contes subséquents étaient bel et bien un prétexte, ou peu s'en fallait. La question demeure toutefois de comprendre pourquoi l'écrivain décida malgré tout de placer ce très court texte en guise d'ouverture générale. À quel piège (rhétorique) le lecteur serait-il prié, à l'instar de la bécasse, de se laisser prendre ? Tout est assez curieux en fait dans ce court propos qui sert d'avant-propos à un recueil dont Maupassant s'opposa à ce qu'on en changeât le titre pour des raisons que son éditeur ne connaîtra pas : 
J'ai les yeux fort malades et je ne puis guère écrire. Mais vous, qui n'avez pas mal aux yeux, vous ne me donnez pas les nouvelles promises (...). Quant aux Contes de la bécasse, en y songeant, je ne veux pas changer de titre ; c'est une supercherie peu digne, qui sent la réclame de mauvais aloi. Nous conserverons donc l'ancien titre tel quel, bon ou mauvais ${ }^{5}$.

Le dispositif des instances narratives est simple dans son principe. Un narrateur extradiégétique rapporte les menus plaisirs d'un gentilhomme campagnard - « Il adorait les contes, les petits contes polissons, et aussi les histoires vraies arrivées dans son entourage ». Un art de la parole et un plaisir à la conversation, entre hommes et entre pairs. Ce goût du monde mis en récits est redoublé par le scénario intra-diégétique qui veut que :

[...] à l'automne, au moment des chasses, il invitait, comme à l'ancien temps, ses amis, et il aimait entendre au loin les détonations (...). Et le soir, il exigeait de chacun le récit fidèle de sa journée. Et on restait trois heures à table en racontant des coups de fusil.

6 Le récit délègue ainsi par moments la parole à des raconteurs anonymes, selon une convention narrative aussi élémentaire qu'efficace, pour créer des effets de réel d'oralité discursive : «J'entends : "Birr! Birr !" et une compagnie magnifique me part à dix pas. "

7 Ce petit monde de «l'ancien temps » est décrit avec nostalgie et stéréotypie dans ses habitudes amicales et ses mœurs culturelles ${ }^{6}$. Cette délégation de parole est d'ailleurs très limitée et très encadrée, selon un art classique du récit qu'un narrateur anonyme et omniscient contrôle, tel un dieu dans sa création: «Et tous, étonnés, mais réciproquement crédules, s'extasiaient. $»^{7}$ Comme si le crédit à l'art du raconteur et la crédulité à la part du réel se conjuguaient à la satisfaction des convives et à l'ironie amusée du narrateur premier. Mais aussi comme si la communauté homogène du petit public favorisait la croyance aux pouvoirs de la fable qui tend à substituer « au désir de vérité et de connaissance l'accomplissement d'un autre désir, celui de la voix de fiction (...) de vive voix contée » (Marin, 1994, 157-158).

8 Le statut pragmatique de ces dires est conforme au pacte de connivence discursive et de consensus culturel propre aux genres oraux dont le statut générique reste incertain. Un conte, un petit conte polisson, une histoire rapportée de visu, un récit autobiographique factuel? Le régime de vérité est ainsi lui-même ambigu: une « histoire vraie ", un « récit fidèle » et/ou "d'étranges et invraisemblables aventures » où se complaît "l'humeur hâbleuse des chasseurs »? Si le vieux baron prend " un plaisir extrême "४ à ces récits, fussent-ils "étranges et invraisemblables " (l'injonction de vérité et de fidélité au réel s'est donc bien dissipée dans le plaisir à la fiction contée), il doit en être de même pour les convives - et pour les lecteurs eux-mêmes conviés aux banquets des mets et des mots (Jeanneret, 1987). On dirait que Maupassant brasse les diverses acceptions historiques - particulièrement labiles voire contradictoires - du terme «conte » et que cette polysémie confuse brouille les assignations génériques habituelles et conventionnelles. Seul un rite de parole - qui soudain s'impose comme l'horizon narratif du texte - apparaît plus motivé qu'arbitraire. Le récit crée en effet sa propre catégorie ou sous-catégorie discursive, sa scénographie énonciative : « Il existait dans la maison une vieille coutume, appelée le "conte de la Bécasse" ». Comme si les éternelles histoires de chasseurs ou les souvenirs de chasse plus ou moins drôles ne méritaient guère mieux que de servir de faire-valoir à la mise en scène de la coutume du lieu. 


\section{En quête d'auralité}

La mise en abyme des contes dans un récit-cadre comme scène générique affilie bien sûr cette situation discursive à un rituel de contage qui s'inscrit dans une très longue et très riche tradition. Il arrive que cette scénographie intègre dans le texte lui-même des schèmes discursifs de l'oralité et explicite - pour être lu et reçu - « une grande partie du code sémantique de l'univers culturel donné » (Greimas, 1976a, 195)`. C'est en partie la rhétorique ethnoculturelle du récit de la Bécasse ${ }^{10}$.

D'une part, en effet, une sociabilité festive et une convivialité masculine, causeuse et rieuse se réjouissent d'une gamme de récits que l'ethnographe a parfaitement identifiés comme allant de l'illustration narrative d'un savoir technique cynégétique à «la galéjade mettant en général en scène un tireur maladroit qui fait sans le vouloir une chasse extraordinaire (il tue un vol de palombes d'un coup de feu; il tue un sanglier en tirant un lapin)", ou rentre à la maison invraisemblablement bredouille (Fabre et Lacroix, 1974, 128) ${ }^{11}$. Les chasseurs racontent des histoires de chasse. C'est leur genre. Il en va ainsi dans notre récit, de celui de fanfaron - «J'ajuste : pif ! paf ! j'en vois tomber une pluie, une vraie pluie. Il y a en avait sept !»- à l'histoire «drôle » entrée dans le répertoire de la petite communauté des chasseurs-conteurs :

Quelques-unes avaient fait date et revenaient régulièrement. L'histoire d'un lapin que le petit vicomte de Bourril avait manqué dans son vestibule faisait se tordre chaque année de la même façon.

11 Cette "histoire » insérée dans la trame de l'écriture littéraire constitue un fragment fictif d'oralité narrative d'une communauté définie qui seule lui donnerait vie (un répertoire qu'elle invente, transmet et apprécie). Elle obéirait ainsi aux conditions d'interactions de l'oralité ancienne: «Une œuvre folklorique suppose un groupe qui l'accepte et la sanctionne » in vivo (Bogatyrev et Jakobson, 1973, 60-63). À défaut, elle s'étiole et disparaît. Il n'y a donc pas plus rite qu'art verbal oral sans une "sanction " d'une communauté d'intérêt à la fable (sa conception, sa transmission, son écoute). C'est le cas pour quelques-uns précisément de ces micro-récits qui à la fois sont des classiques (ils font "date»), sont "régulièrement» redits et sont reçus "chaque année " de la "même façon». Il y a en effet une sorte d'homologie entre ces historiettes amusantes qui font songer aux mondes de l'imagerie folklorique ou populaire (le chasseur prodigieux, le chasseur maladroit) et le rire carnavalesque des convives: "suffoquer de gaieté » pour "quelque culbute inattendue et drôle », "rire aux larmes », «se tordre ».

D'autre part, l'organisation narrative même du texte mime le dispositif discursif classique des situations de contage qui progresse généralement du quotidien référentiel au plus fabuleux : "quoi de nouveau?»; «le récit fidèle de sa journée »; «étranges et invraisemblables aventures »; « conter une histoire ». Nicole Belmont fait judicieusement observer que les grandes ou les petites veillées à la chandelle (ici un repas de chasseurs) ne débutaient point par la narration directe des contes. La "première partie de la veillée était le temps des "nouvelles locales, chansons, devinettes, récits légendaires considérés comme véridiques".» Ce n'est que "plus tard ", plus avant dans la nuit propice à des expériences verbales plus déroutantes "qu'on priait un conteur de raconter un des récits qu'il connaissait» (Belmont, 1999, 129) ${ }^{12}$. 
13 Il n'est pas enfin jusqu'aux contraintes de parole qui n'affilie la Bécasse à la situation de contage où « un rituel précis inaugure et clôture l'activité narrative ». En effet, il est de coutume qu'au début le conteur doive "se faire prier ». Sous divers prétextes (il est fatigué, il a oublié, etc.), il refuse ou diffère, jusqu'à ce qu'un sourire entendu signale à l'assemblée qu'il « en tient un! » (Fabre et Lacroix, 1974, 133). Cette résistance au dire fait donc partie du rite qui a charge de lever les censures ou les réserves, le récit d'une aventure ou d'une mésaventure exposant toujours à l'inattendu ou à l'imprévisible d'un récit. Ainsi peut-on comprendre l'ethnologique du rite imaginé par Maupassant et son impératif contre-don :

La même cérémonie recommençait à chaque dîner (...). L'élu du hasard devait, sur l'ordre du baron, conter une histoire (...).

14 Ce dispositif sémio-rhétorique et cette feintise discursive ludique trouvent peut-être tout leur sens dans la quête d'une aura - un hic et nunc d'un rapport direct à l'œuvre, l'unicité et (donc) l'authenticité de sa production sociale et personnelle - qui serait comme la conquête d'une oralité, l'aura de l'oralité très exactement, dont le $\mathrm{XIX}^{\mathrm{e}}$ siècle pouvait encore avoir la mélancolique mémoire :

L'aura n'existe pas avant la reproduction, qui en serait comme le moment de destruction. L'aura ne prend véritablement forme... que dans son épuisement, généré par l'essor inéluctable des techniques de reproduction (...). C'est au moment de sa destruction radicale que l'aura peut apparaître (...).

(Tackels, 2001).

15 Ce n'est sans doute pas un hasard si c'est dans les années 1880 que Maupassant essaie de capter cette "aura du réel » dont parle Walter Benjamin, en un moment où la culture folklorique (largement orale) devient un objet de compilation érudite ${ }^{13}$ et où l'école devient obligatoire pour tous ${ }^{14}$. Le vieux baron - «esprit lettré du dernier siècle»- aime ainsi conjuguer les vifs plaisirs de l'échange verbal et, à défaut, la pratique des livres : "Le reste du temps il lisait ». Ces deux régimes de communication coexistent donc (récits dits et récits écrits, lire et conter, conter par écrit) selon des configurations plus ou moins originales, comme si l'écriture était alors songeuse de l'oralité conteuse. Ce processus créatif (hybridation discursive et syncrétisme intraculturel) trouve aussi ses sources et ses ressources dans les expériences langagières et narratives des écrivains eux-mêmes (Montaigne, Perrault, Chateaubriand, Proust), leurs créances enfantines dans les charmes de la culture orale parmi les petites gens de la domesticité.

Le jeune Guy avait « dix ou douze ans ». Le souvenir d'une "vieille couturière qui venait une fois par semaine, tous les mardis, raccommoder le linge » chez ses parents lui restera, étrangement "vif et tenace » : «Je m'étonne de ne pouvoir passer un jour, un seul jour, sans que la figure de la mère Clochette ne se retrace devant mes yeux, telle que je la connus, autrefois. » C'était une « haute femme, maigre et barbue ». Elle boitait, et :

[...] sa tête toujours coiffée d'un énorme bonnet blanc, dont les rubans lui flottaient dans le dos, semblait traverser l'horizon (...) à chacun de ses mouvements.

J'adorais cette mère Clochette. Aussitôt levé je montais dans la lingerie où je la trouvais installée à coudre (...). Elle me contait des histoires, tout en reprisant le linge avec ses longs doigts crochus, qui étaient vifs (...).

Elle me contait les événements du bourg, l'histoire d'une vache qui s'était sauvée de l'étable et qu'on avait retrouvée, un matin, devant le moulin de Prosper Malet, regardant tourner les ailes de bois, ou l'histoire d'un œuf de poule découvert dans le clocher de l'église sans qu'on eût jamais compris quelle bête était venue le 
pondre là, ou l'histoire du chien de Jean-Jean Pilas, qui avait été reprendre à dix lieues du village la culotte de son maître volée par un passant tandis qu'elle séchait devant la porte après une course à la pluie.

17 La poésie de ce bestiaire local et folklorique, fabuleux et rustique, enchante l'enfant: «Elle me contait ces naïves aventures de telle façon qu'elles prenaient en mon esprit des proportions de drames inoubliables, de poèmes grandioses et mystérieux (...). »

Hélas la belle histoire est tragique :

Un mardi, comme j'avais passé toute la matinée à écouter la mère Clochette, je voulus remonter près d'elle, dans la journée, après avoir été cueillir des noisettes avec le domestique, au bois des Hallets, derrière la ferme de Noirpré (...). Or, en ouvrant la porte de la lingerie, j'aperçus la vieille couturière étendue sur le sol, à côté de sa chaise, la face par terre, les bras allongés, tenant encore son aiguille d'une main, et de l'autre, une de mes chemises (...). La mère Clochette était morte.

L'écrivain, dans une posture d'un romantisme inattendu (la vieille, étrange et pauvre femme, la lingère conteuse, l'enfance aux champs, les récits topiques et folkloriques, l'amour et la mort), conclut cette évocation par une remarque désenchantée sur les limites de la littérature écrite, condamnée à être « inauthentique $»^{15}$ :

Les contes ingénieux inventés par des poètes et que me narrait ma mère le soir, n'avaient point cette saveur, cette ampleur, cette puissance des récits de la paysanne ${ }^{16}$

20 Le dit de la vache échappée qui regarde tourner les ailes de bois du moulin, le motif de l'œuf de poule dans le clocher de l'église et le récit du chien prodigieux de Jean-Jean Pilas sont-ils si loin dans la conscience étonnée ou émerveillée de l'enfant de l'aura définie comme "l'ici et maintenant de l'œuvre» et tout autant comme "l'unique apparition d'un lointain, si proche soit-il»? C'est l'irruption de la poésie dans le quotidien, la présence unique de la parole et l'authenticité de l'écoute, l'appropriation par corps ${ }^{17}$ et la familiarité de la voix, l'expérience affective et mémorielle d'un passé dont la familière étrangeté est toujours proche. La littérature écrite et sa lecture - de ce point de vue - ne peuvent être que la trace de l'absence et de l'absent. Or, «dans la trace nous nous emparons de la chose » alors que « dans l'aura elle s'empare de nous » (Benjamin, 2006, 464) ${ }^{18}$. En effet...

\section{La « coutume » du contage}

21 La littérature offre de nombreux exemples de cette réappropriation des récits in situ ou en situation et Maupassant s'est plu à réinventer le chronotope de ces sociabilités conteuses d'autrefois, et de naguère.

\section{Les raconteurs de vive voix}

C'est d'abord, en effet, dans le champ de positions littéraires, la parodie des Soirées de Médan (1880), comme si Maupassant qui à l'époque était un prétendant - «je ne suis encore rien comme littérateur $»-$ s'accordait quelques mois seulement après le succès retentissant de Boule de Suif $(1880)^{19}$ un droit de parole ironique voire caricaturale de petit maître à l'encontre du maître :

Nous nous trouvions réunis, l'été, chez Zola, dans sa propriété de Médan. Pendant les longues digestions des longs repas (car nous sommes tous gourmands et gourmets, et Zola mange à lui seul comme trois romanciers ordinaires), nous 
causions. Il nous racontait ses futurs romans, ses idées littéraires, ses opinions sur toutes choses. Quelquefois il prenait un fusil, qu'il manœuvrait en myope, et tout en parlant, il tirait sur des touffes d'herbes que nous lui affirmions être des oiseaux, s'étonnant considérablement quand il ne retrouvait aucun cadavre.

Il suffirait de comparer ce témoignage anecdotique que Maupassant livrait en 1880 au journal le Gaulois sur «les gourmets et les gourmands " de Médan pour penser à la Bécasse (1882) où les volubiles et joyeux amis restent "trois heures à table ", et à cet hôte certes de «commerce aimable » et autoritaire, mais aussi aimablement crédule sinon un peu gâteux :

Par les jours de soleil (...), un domestique, derrière son dos, tenait les fusils, les chargeait et les passait à son maître ; un autre valet, caché dans un massif, lâchait un pigeon de temps en temps, à intervalles irréguliers, pour que le baron ne fût pas prévenu et demeurât en éveil.

Et, du matin au soir, il tirait les oiseaux rapides, se désolant quand il s'était laissé surprendre, et riant aux larmes quand la bête tombait d'aplomb (...). Il se tournait alors vers le garçon qui chargeait les armes, et il demandait, en suffoquant de gaieté :

«Y est-il, celui-là, Joseph ! As-tu vu comme il est descendu?

Et Joseph répondait invariablement :

- Oh! Monsieur le baron ne les manque pas. »

Le scénario d'ensemble du récit à contraintes y est aussi énoncé, tout comme le plaisir à la vive voix du récit :

Or, par une nuit de pleine lune, nous parlions de Mérimée, dont les dames disaient : «Quel charmant conteur !» (...). On en vint à parcourir tous les conteurs célèbres et à vanter les raconteurs de vive voix, dont le plus merveilleux, à notre connaissance, est le grand Russe Tourgueneff, ce maître presque français ; Paul Alexis prétendait qu'un conte écrit est très difficile à faire (...).

Mais Zola trouva que c'était une idée, qu'il fallait se dire des histoires. L'invention nous fit rire, et on convint, pour augmenter la difficulté, que le cadre choisi par le premier serait conservé par les autres, qui y placeraient des aventures différentes ${ }^{20}$.

Cet intertexte n'aurait guère d'autre intérêt ici qu'en termes d'héritage littéraire et de retournement de subordination symbolique s'il n'inscrivait aussi La Bécasse dans une logique de contre-don "agonistique ", tout en réitérant la fascination des écrivains (naturalistes) pour la performance narrative orale qui conjugue art du récit et présence de la voix ${ }^{21}$.

Cette nostalgie est thématisée dans les premières pages d'un récit de Balzac, autre grand modèle de Maupassant. Autre étude de femme (1831) met en effet en scène et en valeur une situation de communication où le "phénomène oral » tient le haut du pavé parisien. Écoutons le romancier nous expliquer comment s'organisent ces soirées « conteuses » :

À Paris, il se rencontre toujours deux soirées dans les bals ou dans les raouts. D'abord une soirée officielle à laquelle assistent les personnes priées, un beau monde qui s'ennuie. Chacun pose pour le voisin. La plupart des jeunes femmes ne viennent que pour une seule personne. Quand chaque femme s'est assurée qu'elle est la plus belle pour cette personne et que cette opinion a pu être partagée par quelques autres (...) les groupes s'éclaircissent, les indifférents s'en vont, les bougies brûlent dans les bobèches; la maîtresse de la maison arrête alors quelques artistes, des gens gais, des amis, en leur disant : - Restez, nous soupons entre nous.

Le cadre amical et convivial est posé et ce petit monde électif se plaît à retrouver, comme dans la « province » du vieux baron, « l'ancien esprit de notre joyeux pays » : 
On se rassemble dans un petit salon. La seconde, la véritable soirée a lieu ; soirée où, comme sous l'ancien régime, chacun entend ce qui se dit, où la conversation est générale, où l'on est forcé d'avoir de l'esprit et de contribuer à l'amusement public (...). Enfin, le plaisir commence là où le raout finit (...). Cette seconde soirée est donc, en France, dans quelques maisons, une heureuse protestation de l'ancien esprit de notre joyeux pays (...). Là, nul ne pense à garder sa pensée pour un drame ; et, dans un récit, personne ne voit un livre à faire (...).

\section{fadette :}

Je voudrais écouter ce paysan qui chantait tout à l'heure, ou toi-même, si tu voulais me dire un de ces contes que le chanvreur de ton village t'apprend durant les veillées d'automne.

«Le laboureur ne chantera plus aujourd'hui, répondis-je, car le soleil est couché (...). Mais je connais le chanvreur ; il ne demande qu'à raconter des histoires, et il ne demeure pas loin d'ici. Nous pouvons bien aller l'inviter à souper (...). - Eh bien, allons le chercher (...), et demain tu écriras son récit » (...).

Le chanvreur ayant bien soupé, et voyant à sa droite un grand pichet de vin blanc, à sa gauche un pot de tabac pour charger sa pipe à discrétion toute la soirée, nous raconta l'histoire suivante (...).

Le père Barbeau de la Cosse n'était pas mal dans ses affaires (...).

(Sand, $1849,37-38$ et 41$)^{22}$.

Ces mises en scène de la parole tiennent aussi peut-être au fait que déjà au XIX siècle, 
[...] l'art de conter est en train de se perdre. Il est de plus en plus rare de rencontrer des gens qui sachent raconter une histoire. Et s'il advient qu'en société quelqu'un réclame une histoire, une gêne de plus en plus manifeste se fait de plus en plus sentir dans l'assistance. C'est comme si nous avions été privés d'une faculté qui nous semblait inaliénable, la plus assurée de toutes: la faculté d'échanger des expériences.

(Benjamin, $2000 \mathrm{~b}, 115)^{23}$.

Tout se passe en tout cas comme si était particulièrement vive dans le monde de la culture écrite la conscience que «l'expérience transmise de bouche en bouche était la source à laquelle tous les conteurs ont puisé » et que parmi ceux qui ont " couché leurs récits par écrit ", les plus grands étaient ceux dont le texte "s'éloigne le moins de la parole des innombrables conteurs anonymes" (Benjamin, 2000 b, 116). C'est l'imprimerie qui a progressivement «éliminé le récit de la parole vivante (...) : le lieu de naissance du roman, c'est l'individu dans sa solitude» (Benjamin, 2000 b, 121). Pareillement, celui qui

[...] écoute une histoire se trouve en compagnie du conteur (même celui qui la lit partage cette expérience) ; le lecteur de roman, lui, est solitaire (...). Ce qui attire le lecteur vers le roman, c'est l'espérance de réchauffer sa vie transie à la flamme d'une mort dont il lit le récit.

(Benjamin, 2000 b, 139).

Inversement, "le conteur c'est l'homme qui pourrait laisser la mèche de sa vie se consumer entièrement à la douce flamme de ses récits » (Benjamin, 2000 b, 150).

\section{S'en laisser conter (ou pas)}

Il conviendrait donc de s'en laisser conter, surtout si l'on admet avec J. Joubert que « les contes qui ont passé par la veillée en valent mieux »... ${ }^{24}$. C'est du moins ici l'implicite (à peine) pacte de lecture.

37 Le vieux baron dans son fauteuil-lit - alter ego dans la fiction de son lecteur... - ne semble-t-il pas consentir lui-même bien aisément à la feintise ludique de son entourage? Il se laisse en effet et de toute évidence volontiers duper sinon plumer, comme on a vu, vrai « pigeon » (pour rire) de l'histoire (cf. p. 109).

À ce petit jeu de pigeon qui vole puis qui fait la culbute («les petits contes polissons » ne sont jamais très loin), les lecteurs sont priés de se laisser prendre, "crédules " comme il se doit. Se laisser attraper même, comme on l'a déjà pressenti. Ne dit-on pas familièrement que la bécasse est bridée pour dire, sur un mode imagé, qu'une " personne s'est laissée surprendre à une tromperie qu'on lui avait préparée $»^{25}$ ?

La « vieille coutume » du " vieux baron » (étrange insistance sur l'ancienneté présumée de ce petit rite domestique) tourne si l'on peut dire autour d'une sorte de dispositif artisanal bricolé tant bien que mal. On l'a vu, il s'agit de fixer la tête de l'une des bécasses ointe de graisse sur un tourniquet plus ou moins ingénieux composé d'un bouchon et d'un goulot de bouteille, «le tout en équilibre au moyen de petits bâtons croisées comme des balanciers ${ }^{26}$. Il suffit alors, d'un coup de doigt, de faire "vivement pivoter ce joujou », et le «long bec pointu » désignera «l'élu du hasard» qui devient comme maître et jouisseur de « toutes les têtes ».

41 Ces chasseurs font ainsi joujou, comme le texte fait joujou avec le langage : simple mot d'esprit (un pigeon peut chasser l'autre; le baron adore les «contes », l'abbé casse), 
parodie assez transparente d'une technique littéraire ancienne (les contes de Boccace) ${ }^{27}$, allusion érotique indirecte (monde d'hommes qui manipulent « aiguilles » et « épingles ») ${ }^{28}$, performance orale traditionnelle (conter/compter) : « Tous les convives comptaient ensemble, d'une voix forte : «Une, - deux, - trois ». Mais surtout, outre que le mot a le charme un peu régressif de l'onomatopée, joujou désigne tout particulièrement un petit jouet qui sert à l'amusement des enfants, plus généralement un petit objet mignon ou compliqué, mais sans réelle valeur marchande même s'il peut "être apprécié des esprits légers ». Ou des libertins d'un autre siècle. À quoi joue-t-on vraiment avec ce pivotant joujou?

\section{Le roi et la reine}

43 À vrai dire, ce rite original et presque enfantin est structuré à l'image d'un autre rite qui met lui aussi en scène de jeunes et grands enfants, une joyeuse tablée, le hasard et son rite, les soirées bavardes, bref un dispositif festif, cyclique, hivernal et carnavalesque : la fête des Rois. Il y a en effet chaque soir chez le « roi des chasseurs » un temps de ritualité où comme pour le tirage au sort de la fève du gâteau des Rois « tout le monde se tait » et attend. Cette convivialité ludique (tête) et coutumière (fève) repose chez le baron sur le hasard d'un tourniquet que le maître de cérémonie actionne sous le contrôle des dîneurs qui font chorus :

Tous les convives comptaient ensemble, d'une voix forte :

«Une, - deux, - trois ».

Et le baron, d'un coup de doigt faisait pivoter ce joujou.

Mais, à l'image de la cérémonie traditionnelle du Roi-Boit, ici le «maitre de toutes les têtes ", souverain d'un soir, doit compenser par un récit de son invention le privilège unique de croquer « une à une » ces têtes qui lui sont sacrifiées, "régal exquis », plaisir régalien... Ce roi pour rire et pour dire déguste devant les autres convives « la reine des gibiers » et les autres convives, comme il est d'usage, se doivent, "à chaque fois ", de

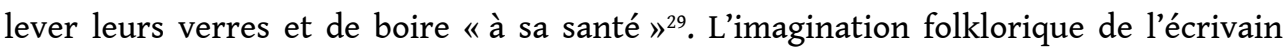
invente ainsi une variation coutumière où le contre-don n'est pas d'offrir la prochaine galette et de choisir une reine, mais de consommer la reine ("exclamations de plaisir $")^{30}$ et de dire un conte ${ }^{31}$. Comme dans la véritable fête, jadis :

À notre sérée (veillée) des Rois et du Roy boit, et à la mascarade de ce jour, notre Roy de la fève voyant que le jour était propre à parler des masques, en va faire le premier conte, à la charge que chacun ferait le sien propre à ce jour (...) : «Vous savez que sous le couvert des masques il se fait des marchés bien cornus » (...). Or est-il arrivé, ajouta notre Roy, il n'y a pas longtemps, que plusieurs gens mariés et autres s'avisèrent après le souper d'aller en une assemblée où la plupart de leurs femmes étaient. Étant entrés fort bien masqués et déguisés, en la salle où était le bal, les violons et la danse cessent (...). Le mari ne laissa pas de retourner en la danse avec les autres ses compagnons, après toutefois s'être remarqué à grand peine, à cause des cornes qui lui étaient crues. Le Roy mit fin à son conte et jura qu'il n'était pas de la mommerie.

Et les histoires s'enchaînaient dans la joyeuse gaieté de ce jour des Rois qui ouvre dans le calendrier folklorique la période des festivités de Carnaval :

Une fesse-tondue dit alors qu'il avait grande envie de faire un conte à propos des mascarades, n'était qu'il avait peur en parlant latin de payer l'amende, tant la coutume est une autre nature (...). Il commença ainsi : "J'ai grande envie de faire une mascarade avec ma maîtresse : on m'a assuré que si elle est habillé de paille et moi vêtu d'ambre (que les latins appellent succinum), en m'approchant d'elle elle sera contrainte de se joindre à moi (...). Nous serons tellement joints que la séparation en sera bien difficile, à moins que l'ambre ne soit frotté d'huile » (...). Il 
fut dit encore un conte de mascarade, lequel dès l'entrée étant connu de tous, lui fut dit, monsieur le cocu, vous plait-il pas démasquer?

(Bouchet, 1608, 104-105). d'ailleurs d'autres «royautés» carnavalesques où résonnait ce cri: «Le Roi boit!»C'était le cas par exemple - jusqu'à la fin du xix ${ }^{e}$ siècle - lors des rituelles décapitations de l'oie ou du coq (Van Gennep, 1947, 958-961; Méchin, 1992), le plus souvent le Jeudi-Gras, le Jeudi-Jeudiot. Les joueurs, les yeux bandés et armés d'un bâton, tentaient de décapiter un coq. Chaque tentative se payait d'une redevance perçue par les garçons de la fête. Le vainqueur brandissait le volatile au sommet d'une longue perche: il était sacré "Roi des poules». Le perdant était le "Roi dépouillé» (Gaignebet, 1968, 35-44 ; 1969, 105-108 ; Gaignebet et Lajoux, 1985, 170-173). Il existait bien d'autres jeux d'adresse ${ }^{32}$ très répandus depuis le Moyen Âge (parodie ou version populaire des tournois et joutes chevaleresques ?) où Mardi-Gras cette fois était figuré par « un coq que l'on enfouissait dans le sol jusqu'au cou. Les jeunes gens du pays assemblés vers la fin de la nuit sur la place du village, les yeux bandés, un sabre à la main, s'escrimaient à qui mieux mieux jusqu'à ce que la tête de l'animal ait complètement détachée du tronc ». Ce « sacrifice » du coq se faisait bien sûr «à grand renfort de cris, de musique et de chants » (Van Gennep, 1947, 958 et 1102-1105). Ailleurs encore, «le coq est enfermé dans un panier ou une poterie d'où sa tête dépasse (cf. notre colin-maillard) et c'est à l'aide d'un maillet ou en lançant un bâton que l'on cherche à le décapiter » (Gaignebet et Lajoux, 1985, 170-173)33. Le « roi » se choisit une reine et le tout se clôt par un festin, au frais du vainqueur, en bonne logique de l'échange symbolique (Van Gennep, 1947, 959). des mondes ruraux d'autrefois. Elle correspond en tout cas à la définition du rite comme "paroles proférées, gestes accomplis, objets manipulés " (LéviStrauss, 1971, 600). Le rituel assigne souvent aux gestes (faire pivoter) et aux objets (tourniquet) une fonction sémiotique qui remplace les paroles voire qui «évite de parler» (Lévi-Strauss, 1971,600): "Tout le monde se taisait dans l'anxiété de l'attente ». Aussi ne peut-on s'étonner de l'extrême précision des dispositifs matériels et techniques du rite de la bécasse (plat, onction, aiguille, bec, chandelle, épingle, bouchon, petits bâtons, etc.). Mais ce que nous décrivons comme rite est qualifié par le texte de " cérémonie ». Une cérémonie rituelle en effet, et sa liturgie ${ }^{34}$. C'est ainsi que le geste de l'officiant rappelle sur un mode sacrilège (plus spontanément perçu sans doute par le lectorat du XIXe siècle), les sacrifices bibliques:

Si l'on offre en holocauste au Seigneur des oiseaux, savoir des tourterelles et des petits de colombe, le prêtre offrira l'hostie à l'autel, et lui tournant avec violence la tête en arrière sur le cou, il lui fera une ouverture et une plaie par laquelle il fera couler le sang sur le bord de l'autel (...). Il rompra les ailes sans les couper et sans diviser l'hostie avec le fer, et il la brûlera sur l'autel après avoir mis le feu sous le bois. C'est un holocauste offert au Seigneur, et une oblation qui lui est d'une odeur très agréable.

(Lévitique, 1-14-17) ${ }^{35}$. 
des Rats/Veaux peut s'entendre comme une version profane et profanatoire de l'adoration du Veau d'or ${ }^{36}$. Maupassant est coutumier de ces parodies du sacré (Privat, 2008, 127-145 ; Bonnefis, 2009, 15-48) ${ }^{37}$. Et le sacrifice coutumier (l'hostie est le nom qui désigne la victime sacrificielle dans l'Ancien Testament) résonne ainsi comme la parodia sacra de la Cène (dîner, assemblée d'hommes, communion du vin et de la chair) et plus généralement de l'office divin (officier comme un évêque, onction des têtes, chandelle allumée, silence religieux, chœur, communion de l'élu) ${ }^{38}$. Mikhaïl Bakhtine a souligné à quel point

[...] le jeu libre avec les choses sacrées constitue la teneur essentielle du symposium grotesque médiéval (...). On y trouve presque toujours un élément de travestissement parodique de la Cène : textes sacrés, paroles liturgiques, fragments de prières retournées à l'envers, accompagnaient littéralement chacun des verres, chacune des bouchées (...).

(Bakhtine, 1970, 294-295).

51 Et Bakhtine ajoute à propos de ce « libertinage de table » : «Ces travestis de table (qui vient encore aujourd'hui) sont l'héritage du Moyen Âge, autant de débris du symposion grotesque ".

(Bakhtine, 1970, 286-293) ${ }^{39}$. Il n'est pas enfin jusqu'à la présence dévouée du serviteur Joseph, le valet d'armes, et plus encore la répétition du mot « crâne » - « Jésus, portant sa croix, arriva au lieu du crâne, qui se nomme en hébreu Golgotha » (Jean, 19.17) - qui ne contribuent à créer cet arrière-plan religieux et irréligieux ${ }^{40}$ où les convives «s'extasient ». Ce «crâne » couronne un mécanisme qui, pareil à un coq de clocher, pivote à la pointe d'un édifice, flèche sacrée de l'église, ici, avec sa croix surmontée d'une girouette, là, tête d'épingle surmontée d'une tête d'oiseau, épingle fichée sur le bouchon du goulot d'une (bonne) bouteille... Nul ne saurait plus s'étonner que tout ce bricolage ne soit maintenu en équilibre au moyen de petits "bâtons croisés", forcément croisés ${ }^{41}$. Le "crépitement » de la graisse et la peau "rissolée » donnera d'ailleurs au «crâne suiffé $»^{42}$ une saveur incomparable, la saveur païenne et carnavalesque d'un mets grillé à la flamme nocturne d'une chandelle. La collusion brutale de connotations mystiques et de dénotations païennes est ainsi constitutive de cette cérémonie: convives qui s'exclament, joujou qui pivote, peau qui rissole, élu du hasard ${ }^{43}$, chandelle culinaire, crâne croqué à belles dents, régal exquis, voisins qui louchent, exclamations de plaisir. Le miracle (littéraire) sera la transformation sous nos yeux d'une fiction en une narration, de la chair du sacrifice en l'artifice du récit. Le conte doit être goûté comme un désirable festin de mots, ironique destin des paroles eucharistiques : Prenez et mangez, car ceci est... une tête de bécasse.

\section{Dans un plat toutes les têtes}

Cette parodie des saintes Écritures présente un ultime trait d'humour grotesque, et tragique en quelque façon. Comment en effet ne pas mettre en relation ces têtes précieuses qui finissent sur un plat (contre un récit) et le saint chef de Jean-Baptiste échangé contre un royaume (ou peu s'en faut), lors du fameux festin d'Hérode :

Un jour propice arriva, lorsque Hérode, à l'anniversaire de sa naissance, donna un festin à ses grands, aux chefs militaires et aux principaux de la Galilée. La fille d'Hérodias entra dans la salle; elle dansa, et plut à Hérode et à ses convives. Le roi dit à la jeune fille : «Demande-moi ce que tu voudras, et je te le donnerai (...). - Je veux que tu me donnes à l'instant, sur un plat, la tête de Jean-Baptiste ». Le roi [...] envoya sur-le-champ un garde, avec ordre d'apporter la tête de Jean-Baptiste. Le garde alla décapiter Jean dans la prison, et apporta la tête sur un plat.

(Marc, 6, 21-68-73) $)^{44}$. 
La Bécasse trace ainsi, une fois encore, un contre-point trivial à la légende sacrée de Salomé, la princesse dont la danse change le destin des hommes et des dieux (Gauthier, 2008), et un contre-point non moins désacralisant à l'intertexte flaubertien :

«Je veux que tu me donnes dans un plat, la tête...Elle avait oublié le nom, mais reprit en souriant : - La tête de Iaokanann! (...) ». Il était contraint par sa parole (...). La tête entra (...) et quand il l'eut mise sur un plat, il l'offrit à Salomé.

(Flaubert, 1877).

L'isotopie de toutes ces têtes sacrificielles, poly-isotopie religieuse et sexuelle, artistique $^{45}$ et folklorique, culinaire ${ }^{46}$ et politique aussi ${ }^{47}$, est structurée par le schème anthropologique de ce don et contre-don où un conte profane s'échange contre un mythe sacré, et une tête d'oiseau de passage contre une tête de prophète.

\section{Le conte de la bécasse ou l'obligation de rendre}

Cette «vieille coutume» de la maison s'appelait donc «le conte de la bécasse ». Le conte est une « coutume » et la bécasse est un « conte». Ce texte liminaire - construit selon une homologie structurelle qui conjoint rite et récit (Scarpa, 2009, 104-105, 183-192, 219-229) - se développe en effet selon une logique (dissymétrique) de l'échange. C'est en effet une dynamique du don et du contre-don qui se manifeste explicitement, selon la logique maussienne de la triple obligation: obligation de donner - obligation de recevoir - obligation de rendre. Il n'est pas surprenant qu'un scénario qui repose sur l'hospitalité, la chasse, le banquet et la parole, soit marqué du sceau de l'obligation et de la réciprocité. Mais si l'on y regarde de plus près, une gradation dans l'impératif se dessine clairement: d'abord, l'hôte, maitre de cérémonie, « demande », puis il « exige de chacun », enfin il donne « ordre ».

\section{Il demande}

Cet homme de commerce aimable et dont le fauteuil est " pareil à un lit ", chasse, parle ou lit. Il lit comme tout lecteur en un sens, même si lui est «cloué » à son fauteuil par une paralysie des jambes : «Dès qu'un ami rentrait chez lui, il demandait: «Eh bien, quoi de nouveau ? Et il savait interroger à la façon d'un juge d'instruction ». C'est dire si la lecture ne lui suffit pas, si l'hospitalité se monnaye en art de la conversation : le récit du monde est un contre-don narratif et impératif offert à l'hôte. Comme si le monde avait ses secrets et le raconteur ses devoirs. Le lecteur n'en saura pas plus.

\section{Il exige}

Le vieux chasseur invite ses amis pour les chasses d'automne et le soir donc il " exige " de chacun le récit fidèle de sa journée. Les histoires de chasse peuvent durer "trois heures ", comme si le compte du temps n'avait plus cours. L'hôte offre l'hospitalité autour d'une bonne table; les amis offrent en contre-don leur «humeur hâbleuse ». Chaque année se joue en effet une sorte de potlatch où les invités rivalisent de virtuosité verbale et de fécondité narrative (étranges et invraisemblables aventures), où les récits flirtent avec la mémoire de très anciennes cosmologies (" une compagnie magnifique [...], une pluie, une vraie pluie » de bécasses) ${ }^{48}$. Ces fables qui font « date » en tout cas composent le répertoire rituel des "orateurs » qui, tout "étonnés" qu'ils soient, 
«s'extasient»: «Il y a en avaient sept!» En somme, une réjouissante parodie du miraculeux ou des prodiges de la Nature rôde parmi la communauté des commensaux, invraisemblable don magique ou bénédiction du ciel qui tombe sur ces apôtres de la blague réunis rituellement pour une pentecôte païenne, gourmande et festive : «La même cérémonie recommençait à chaque dîner ". Comme si cette "abondance de richesses" était tout autant la cause que la conséquence de leurs prestations symboliques; comme si l'imaginaire du texte était travaillé par cette fameuse économie du don qui pose que « les échanges de cadeaux entre les hommes incitent les esprits des morts, les dieux, les choses, les animaux, la nature à être généreux envers eux» (Mauss, 2010, 92).

Le texte se déploie ainsi comme une logique symbolique où le code cynégétique et le code religieux, le code sociologique et le code linguistique, le code ritique et le code gastronomique s'emboîtent pour composer un fait narratif total. Comme si se tramait sous la plume de Maupassant une logique du don et du contre-don proche de l'esprit de l'échange dans les sociétés archaïques et se maintenait encore dans (grâce à) l'univers des signes littéraires un lien ombilical avec une lointaine raison mythique, une sorte de sourd désir de ré-enchantement anthropologique du monde, sous la charge grotesque, le rire attendu et les plaisirs de la bonne chère ${ }^{49}$.

\section{Il ordonne}

Enfin, comme on a vu, le monopole régalien des têtes se paie d'un long récit, "sur l'ordre du baron». Dans ce type d'offre cérémonielle, "l'obligation de rendre dignement " est en effet "impérative », Mauss assurant même que "l'obligation de rendre est tout le potlatch " (Mauss, 2010, 156, 212). Le maitre des lieux veille ainsi à ce que le festin gourmand pour l'un (une forme de gaspillage ostentatoire et de prodigalité festive) $^{50}$ fasse l'objet pour les autres d'une contre-prestation, un contre-don, le don rituel du conte. Après le vivre, le dire. Et le lire du dire.

Dans ce « rituel » de l'échange réciproque et différencié (Lévi-Strauss, 1967, 68), il y a bien plus pour sûr que les choses échangées dans la mesure où « le don est à la fois ce qu'il faut faire (l'hospitalité), ce qu'il faut recevoir (les têtes) et ce qui est cependant dangereux à prendre (les récits). C'est que la chose donnée elle-même forme un lien bilatéral et irrévocable, surtout quand c'est un don de nourriture " (Mauss, 2010, 210). C'est le devoir de conter un des Contes de la bécasse, comme un « régal exquis » qu'avec son bec de plume l'écrivain compose ${ }^{51}$ et que le lecteur dans son fauteuil déguste. En (s') imaginant que " celui qui écoute une histoire se trouve en compagnie du conteur ", voire que « celui qui la lit partage cette compagnie » (Benjamin, $2000 \mathrm{~b}, 138)^{52}$.

Ce plaisir d'oralité partagée est ainsi comme le contre-don de l'écriture, l'oralité d'un récit écrit conté imaginairement de bouche à oreille. Mais cette quête se donne à lire comme une nostalgique réjouissance plus que comme une pure jouissance de réciprocité heureuse. La parodie du présent fait aux dieux est une première dissonance anthropologique. L'irruption du calcul monétaire et marchand ${ }^{53}$ dans ce "commerce aimable » tant prisé du baron détruit à son tour, in fine, l'illusion d'un monde solidaire où la richesse serait « amassée puis redistribuée dans le respect mutuel et la générosité réciproque " (Mauss, 2010, 248). Le régal de l'un fait «loucher ses voisins» (vs «les amis ») et le dîneur suprême doit conter/compter une histoire pour « indemniser les 
déshérités $»^{54}$. Ainsi, brutalement, in fine, fait irruption le motif du don rituel (et légal) du mort aux vivants, l'économie de la perte et de la dette. S'il est vrai que «le repas des morts (...) est une occasion de s'inviter et de rendre les invitations " (Mauss, 2010, 200), alors c'est le lecteur lui-même qui est pris dans cette communauté symbolique des morts dont la littérature est le reliquaire :

Tenez, dit M. Mathieu d'Endolin, les bécasses me rappellent une bien sinistre anecdote de la guerre. Vous connaissez ma propriété dans le faubourg de Cormeil. Je l'habitais au moment de l'arrivée des Prussiens. Et ce Mathieu de raconter le sort tragique fait par l'occupant aussi obtus que cruel à l'une de ses pauvres voisines, « une espèce de folle, dont l'esprit s'était égaré sous les coups du malheur (...) ». Or, il arriva, continue le chroniqueur, qu'à l'automne suivant « les bécasses passèrent en masse ; et, comme ma goutte me laissait un peu de répit, je me traînai jusqu'à la forêt. J'avais déjà tué quatre ou cinq oiseaux à long bec, quand j'en abattis un qui disparut dans un fossé plein de branches. Je fus obligé d'y descendre pour y ramasser ma bête. Je la trouvai tombée auprès d'une tête de mort. Et brusquement le souvenir de la folle m'arriva dans la poitrine comme un coup de poing (...). Ils l'avaient abandonnée (...) dans la forêt froide et déserte (...) ; elle s'était laissée mourir sous l'épais et léger duvet des neiges et sans remuer le bras ou la jambe. Puis les loups l'avaient dévorée (...). J'ai gardé ce triste ossement ».

(Maupassant, la Folle) ${ }^{55}$.

La troisième limite qui parasite l'entre-soi du dire, c'est la mise par écrit du rituel de contage qui dissocie (détruit?) fatalement l'expérience «authentique» de la parole conteuse ("valeur originelle et première de l'œuvre d'art » selon W. Benjamin) et sa reproduction mécanique ${ }^{56}$. Ainsi la bécasse se voit-elle clouer le bec. Il n'est plus de bon bec que du bec de la plume. L'oiseau augural de l'automne et des passages n'est plus que le joujou du hasard pour des hommes qui jouent à imiter le langage des oiseaux (birr ! birr !57), sinon le langage des enfants (pif ! paf !) et pour un écrivain dont le porte-plume serait comme un porte-voix des rites de l'écrit. Le don « incomparable » est toujours un défi... À en perdre la tête. Le contre-don symbolique serait la plus-value inépuisable de la littérature comme instance de transfert des univers langagiers et des échanges symboliques.

\section{BIBLIOGRAPHIE}

AARNE, Anti, THOMPSON, Stith, 1964, The types of the Folktale: A classification and Bibliography, Academia Scientiarum Fennica, Helsinki, vol. 75.

ADORNO, Theodor W., BENJAMIN, Walter, 2006, Correspondance 1928-1940, Paris, Gallimard.

ASSERolette, C. (E. Servie), 1890, Ma cuisine, Paris, Plon.

AURICOSTE DE LAZARQUE, Ernest, 1890, Cuisine messine, Metz, A. Béha, Paris, E. Rolland.

BAKHTINE, Mikhaïl, 1970, L'œuvre de François Rabelais et la culture populaire au Moyen Âge et sous la Renaissance, Paris, Gallimard.

BALZAC, Honoré de, 1971, Études de femme, Paris, Le Livre de Poche [1 $1^{\text {re }}$ éd., 1831]. 
BARTHES, Roland, 1970, s/z, Paris, Seuil, p. 95-96.

BELÈZE, G., 1867, Dictionnaire universel de la vie pratique à la ville et à la campagne, Paris, Hachette. BELMONT, Nicole, 1999, Poétique du conte. Essai sur le conte de tradition orale, Paris, Gallimard/Le Langage des contes.

BENHAMOU, Noëlle, 2006, Le Moyen Âge dans l'œuvre de Maupassant. Histoire, légende, poétique, in Luc Bonenfant (dir.), Les bibliothèques médiévales du XIX ${ }^{\mathrm{e}}$ siècle, Études littéraires, vol. XXXVII, $\mathrm{n}^{\circ} 2$, p. 133-149.

BENJAMIN, Walter, 2000a, L'œuvre d'art à l'époque de sa reproductibilité technique, CEuvres III, Paris, Gallimard, coll. «Folio », p. 269-316. Traduit par Maurice de Gandillac, revu par Rainer Rochiltz [ $1^{\text {re }}$ éd., 1935].

BENJAmin, Walter, 2000b, Le conteur, Euvres III, Paris, Gallimard, coll. « Folio », p. 114-151. Traduit par Maurice de Gandillac et Pierre Rusch [1 ${ }^{\text {re }}$ éd., 1936].

BENJAMIN, Walter, 1991, Écrits français, présentés et introduits par J. M. Monnoyer, Paris, Gallimard, coll. «Bibliothèque des idées ».

BENJAMIN, Walter, 2006, Paris, capitale du XIX $\mathrm{X}^{\mathrm{e}}$ siècle. Le livre des passages, Paris, Cerf, Traduit par Jean Lacoste.

La Bible, 1990, Traduction de Lemaître de Sacy, Paris, Robert Laffont, coll. « Bouquins ».

BOGATYReV, Petr et JAKoBson, Roman, 1973, Le folklore, forme spécifique de création, Questions de poétique, Paris, Seuil, p. 59-72 [1 $1^{\text {re }}$ éd., 1929].

BONNEFIS, Philippe, 2009, Comme Maupassant, Lille, Presses universitaires du Septentrion.

воUсHEт, Guillaume, 1608, Des Roys, qu'on crie le Roy-boit, Les Sérées, Paris, Perier, consulté le 23 mars 2015.

CASTELLA, Charles, 2000, Les Contes et Nouvelles réalistes de Maupassant. Lecture sociogénétique, Lausanne, L'Âge d'Homme, Lettera.

DUBOIs, Urbain, 1889, Nouvelle cuisine bourgeoise pour la ville et pour la campagne, Paris, BernardinBéchet.

DUMAS, Alexandre et VuILLEMot, Denis-Joseph, 1873, Grand dictionnaire de cuisine, Paris, Lemerre. FABRE, Daniel et LACROIX, Jacques, 1974, La Tradition orale du conte occitan, I, Paris, PUF.

FABRE, Daniel, 1986, La voie des oiseaux. Sur quelques récits d'apprentissage, L'Homme, $\mathrm{n}^{\circ} 99$, t. XXVI-3, p. 7-40.

FLAUBERT, Gustave, 1966, Hérodias, Trois Contes, Paris, Le Livre de poche, p. 111-152 [1 ${ }^{\text {re }}$ éd., 1877]. GAIGNEBET, Claude, 1968, Sur le Jeudi-Jeudiot, Bulletin folklorique d'Île-de-France, nº 2-3, p. 35-44. GAIGNEBET, Claude, 1969, Jeudi-Jeudiot. Étude du Roi des enfants des écoles dans les textes, du $\mathrm{XIII}^{\mathrm{e}}$ au XX $\mathrm{XX}^{\mathrm{e}}$ siècle, Bulletin folklorique d'île de France, $\mathrm{n}^{\circ}$ 5, p. 105-108.

GAIGNEBET, Claude et LAJOUX, Jean-Dominique, 1985, Art profane et religion populaire au Moyen Âge, Paris.

GAUTHIER, Claudine, 2008, Saint Jean et Salomé. Anthropologie du banquet d'Hérode, Tours, Éditions Lume.

GENETTE, Gérard, 1983, Nouveaux discours du récit, Paris, Le Seuil, coll. « Poétique ». 
GIARD, Anne, 1980, Le conte d'auteur, Cahiers de littérature orale, $\mathrm{n}^{\circ} 8, \mathrm{p} .13-48$.

GREIMAS, Algirdas Julien, 1976a, Sémiotique et sciences sociales, Paris, Seuil.

GREIMAS, Algirdas Julien, 1976b, Maupassant. La sémiotique du texte : exercices pratiques, Paris, Seuil.

JEANNERET, Michel, 1987, Des mets et des mots. Banquets et propos de table à la Renaissance, Paris, Corti.

LÉVI-STRAUSS, Claude, 1967, Les structures élémentaires de la parenté, Paris, Mouton [1 ${ }^{\text {re }}$ éd., 1947].

LÉVI-STRAUSS, Claude, 1971, L'Homme nu. Mythologiques IV, Paris, Plon.

LÉVI-STRAUSS, Claude, 1979, La voie des masques, Paris, Plon.

LÉVI-STRAUSS, Claude, 1985, Le critère de l'authenticité, Anthropologie structurale, Paris, Pocket,

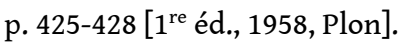

LINTVELT, Jaap, 1993, La polyphonie de l'encadrement dans les contes de Maupassant, in Louis Forestier (dir.), Maupassant et l'écriture, Actes du colloque de Fécamp, Paris, Nathan, p. 173-185.

MAINGUENEAU, Dominique, 2004, La scène d'énonciation, Le discours littéraire, Paris, Armand Colin.

MARIN, Louis, 1994, De la représentation, Paris, Hautes Études-Gallimard-Le Seuil.

MAUPASSANT, Guy de, 1884, Gustave Flaubert. Étude préfaçant le livre Lettres à George Sand, par Gustave Flaubert, Paris, G. Charpentier et Cie.

MAUPASSANT, Guy de, 1887, Les grandes passions, Tout-Paris, 17 décembre 1887, consulté le 23 mars 2015.

MAUPASSANT, Guy de, 1974, Contes et nouvelles, t. I, éd. Louis Forestier, Paris, Gallimard, «Bibliothèque de la Pléiade ».

MAUPASSANT, Guy de, 1979, Contes et nouvelles, t. II, éd. Louis Forestier, Paris, Gallimard, «Bibliothèque de la Pléiade ».

MAUSS, Marcel, 2010 Essai sur le don. Formes et raisons de l'échange dans les sociétés archaïques, Préface

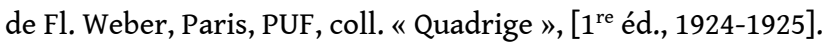

MÉCHIN, Colette, 1992, Bêtes à manger, Usages alimentaires des Français, Nancy, Presses Universitaires de Nancy.

ONG, Walter J., 1973-1974, The Writer's Audience is Always a Fiction, Saint-Louis University, Lincoln Lecture Series. Trad. française, L'auditoire de l'écrivain est toujours une fiction, consulté le 23 mars 2015.

PRIVAT, Jean-Marie, 2004, Si l'oralité m'était contée, Cahiers de littérature orale, nº 56, p. 23-52.

PRIVAT, Jean-Marie, 2008, Boule de Suif ou l'autre Cène, in Laurence Helms et Jean-Louis Cabanès (dir.), Maupassant aujourd'hui, RITM [Recherches Inter-disciplinaires sur les Textes Modernes], 39, Université Paris Ouest-Nanterre La Défense, p. 127-145.

SAND, George, 1969, La petite fadette, Paris, Garnier-Flammarion [1 $1^{\text {re }}$ éd., 1849].

SAND, George, 1976, François le Champi, Paris, Gallimard [1 $1^{\text {re }}$ éd., 1850].

SANGSUE, Daniel, 1988, De seconde main : rire et parodie chez Maupassant, Maupassant. Miroir de la Nouvelle, Colloque de Cerisy, «L'Imaginaire du texte », Saint-Denis, Presses Universitaires de Vincennes, p. 177-187.

SCARPA, Marie, 2009, L'éternelle jeune fille. Une ethnocritique du Rêve de Zola, Paris, Honoré Champion. 
SÉBILLOT, Paul, 1968, Le folklore de France, III, La faune et la flore, Paris, Maisonneuve et Larose

[1 ${ }^{\text {re }}$ éd., 1905].

SUFFEL, Jacques (éd.), 1973, Lettres de Maupassant à Flaubert, reproduites d'après Guy de Maupassant, Correspondance, Évreux, Le Cercle du bibliophile, avec notes de l'auteur. Site de Thierry Selva, Maupassant par les textes, consulté le 23 mars 2015.

TACKELS, Bruno, 2001, La question de l'art ou de la technique, in Petite introduction à Walter Benjamin, Paris, L'Harmattan, p. 61-77.

TOURGUÉNIEV, Yvan, 1981, Mémoires d'un chasseur, Paris, Gallimard « Bibliothèque de la Pléiade », Trad. par Françoise Flamant [1 ${ }^{\text {re }}$ éd., 1874].

VAN GENNEP, Arnold, 1947, Décapitation du coq, Manuel de folklore français contemporain, tome 1, vol. 3, «Cérémonies périodiques cycliques. Carnaval-Carême-Pâques ", Paris, A. et J. Picard et Cie, p. 1104-1105.

VAN GENNEP, Arnold, 1949, Manuel de folklore français contemporain, tome 1, vol. 4. " Les cérémonies périodiques cycliques et saisonnières »; vol. 2. « Cycle de mai - la Saint-Jean », Paris, Éditions A. et J. Picard.

VAN GENNEP, Arnold, 1951, Manuel de folklore français contemporain, tome 1, vol. 5, « Cérémonies agricoles de l'été », Paris, Picard.

VAN GENNEP, Arnold, 1988, Manuel de folklore français contemporain, tome 1, vol. 8, «Cycle des douze jours : de Noël aux Rois », rédigé par Bernadette Guichard, Paris, « Grands manuels Picard ».

WEBER, Eugen, 1983, La fin des terroirs. La modernisation de la France rurale (1870-1914), Paris, Fayard.

\section{ANNEXES}

\section{La Bécasse par Guy DE MAUPASSANT}

Le vieux baron des Ravots avait été pendant quarante ans le roi des chasseurs de sa province. Mais, depuis cinq à six années, une paralysie des jambes le clouait à son fauteuil ; il ne pouvait plus que tirer des pigeons de la fenêtre de son salon ou du haut de son grand perron.

Le reste du temps il lisait.

C'était un homme de commerce aimable chez qui était resté beaucoup de l'esprit lettré du dernier siècle. Il adorait les contes, les petits contes polissons, et aussi les histoires vraies arrivées dans son entourage. Dès qu'un ami entrait chez lui, il demandait :

«Eh bien, rien de nouveau?»

Et il savait interroger à la façon du juge d'instruction.

Par les jours de soleil il faisait rouler devant la porte son large fauteuil pareil à un lit. Un domestique, derrière son dos, tenait les fusils, les chargeait et les passait à son maître ; un autre valet, caché dans un massif, lâchait un pigeon de temps en temps, à intervalles irréguliers, pour que le baron ne fût pas prévenu et demeurât en éveil. Et, du matin au soir, il tirait les oiseaux rapides, se désolant quand il s'était laissé surprendre, et riant aux larmes quand la bête tombait d'aplomb ou faisait quelque culbute inattendue et drôle. Il se tournait alors vers le garçon qui chargeait les armes, et il demandait, en suffoquant de gaieté :

«Y est-il, celui-là, Joseph ! As-tu vu comme il est descendu? 
Et Joseph répondait invariablement :

- Oh! Monsieur le baron ne les manque pas. »

À l'automne, au moment des chasses, il invitait, comme à l'ancien temps, ses amis, et il aimait entendre au loin les détonations. Il les comptait, heureux quand elles se précipitaient.

Et, le soir, il exigeait de chacun le récit fidèle de sa journée.

Et on restait trois heures à table en racontant des coups de fusil.

C'étaient d'étranges et invraisemblables aventures, où se complaisait l'humeur

hâbleuse des chasseurs. Quelques-uns avaient fait date et revenaient régulièrement.

L'histoire d'un lapin que le petit vicomte de Bourril avait manqué dans son vestibule les faisait se tordre chaque année de la même façon. Toutes les cinq minutes un nouvel orateur prononçait :

«J'entends : «Birr ! Birr ! "et une compagnie magnifique me part à dix pas. J’ajuste : pif ! paf ! j'en vois tomber une pluie, une vraie pluie. Il y en avait sept !».

Et tous, étonnés, mais réciproquement crédules, s'extasiaient. Mais il existait dans la maison une vieille coutume, appelée le « conte de la Bécasse ».

$\mathrm{Au}$ moment du passage de cette reine des gibiers, la même cérémonie recommençait à chaque dîner.

Comme il adorait l'incomparable oiseau, on en mangeait tous les soirs un par convive ; mais on avait soin de laisser dans un plat toutes les têtes.

Alors le baron, officiant comme un évêque, se faisait apporter sur une assiette un peu de graisse, oignait avec soin les têtes précieuses en les tenant par le bout de la mince aiguille qui leur sert de bec. Une chandelle allumée était posée près de lui, et tout le monde se taisait, dans l'anxiété de l'attente.

Puis il saisissait un des crânes ainsi préparés, le fixait sur une épingle, piquait l'épingle sur un bouchon, maintenait le tout en équilibre au moyen de petits bâtons croisés comme des balanciers, et plantait délicatement cet appareil sur un goulot de bouteille en manière de tourniquet.

Tous les convives comptaient ensemble, d'une voix forte :

«Une, - deux, - trois».

Et le baron, d'un coup de doigt, faisait vivement pivoter ce joujou.

Celui des invités que désignait, en s'arrêtant, le long bec pointu devenait maître de toutes les têtes, régal exquis qui faisait loucher ses voisins.

Il les prenait une à une et les faisait griller sur la chandelle. La graisse crépitait, la peau rissolée fumait, et l'élu du hasard croquait le crâne suiffé en le tenant par le nez et en poussant des exclamations de plaisir.

Et chaque fois les dîneurs, levant leurs verres, buvaient à sa santé.

Puis, quand il avait achevé le dernier, il devait, sur l'ordre du baron, conter une histoire pour indemniser les déshérités.

Voici quelques-uns de ces récits...

MAUPASSANT, Guy de, La Bécasse (ce conte parut le 5 décembre 1882, dans le journal le Gaulois).

Saisie du texte : Sylvie Pestel pour la collection électronique de la Bibliothèque municipale de Lisieux (20. 05. 1995). Adresse : Bibliothèque municipale - B. P. 216 F 14107 Lisieux cedex.

Diffusion libre et gratuite (freeware). 


\section{NOTES}

1. Guy de MAUPASSANT, « la Bécasse» (1882). Voir l'intégralité de ce court texte en Annexe. Sur l'historique de la publication des Contes de la bécasse, se reporter à l'édition Forestier (1974, 1493-1495).

2. Les repas de chasse recouvrent le calendrier des veillées paysannes: «Les veillées commençaient lorsque les travaux d'automne diminuaient, parfois aux environs de la Toussaint, le plus souvent après la Saint-Martin (11 novembre) et se terminaient en mars ou à Pâques pour l'époque des semailles (...). La culture orale se perpétuait sous forme de contes, de légendes pieuses, d'enseignement sur le royaume du surnaturel, d'explications sur la nature et la vie, de chansons, de proverbes inlassablement répétés (...). Ces vieilles institutions villageoises fonctionnaient encore dans les années 1880 » (Weber, 1983, 594). La bécasse est un mets très recherché ; selon l'ancien régime des goûts (Asserolette, 1890, 209), « La bécasse se mange rôtie, très faisandée et point vidée. C'est pour l'amateur, le gibier fondant par excellence ».

3. Selon les recettes culinaires de l'époque (Belèze, 1867, 189-190), «ce gibier demande à être cuit un peu vert. On ne le vide pas. On découpe la bécasse en tranchant d'abord la tête qui ne se sert pas ». Ce dernier point nous paraît un trait de la culture «bourgeoise » (vs aristocratique) du $\mathrm{XIX}^{\mathrm{e}}$ siècle. Les livres de cuisine de l'époque confirment cette pratique civilisée. Le rédacteur rapporte toutefois que «les anciens chasseurs conservaient précieusement cette tête, et après le dîner ils la faisaient rôtir, enveloppée dans un papier graissé, et en la tournant et retournant par son long bec, à la flamme et au suif d'une chandelle ; ils la croquaient ensuite pour se curer les dents. Avec les chandelles, cette friandise a disparu » (Auricoste de Lazarque, 1890, 131-132). Je remercie vivement Colette Méchin d'avoir attiré mon attention sur ce précieux document qui, selon moi, semble confirmer que Maupassant, très au fait de la chasse et de la cuisine de chasse, a choisi la bécasse pour sa polysémie langagière (l'oiseau, la femme) et sa polyphonie culturelle (les intertextes).

4. À l'origine la Bécasse jouait en fait le rôle de prologue de la Folle, conte de Maupassant publié dans le Gaulois du 5 décembre 1882. On y reviendra.

5. À Victor HAVARD, Sur le Bel-Ami, Antibes, 5 mars 1887. L'éditeur HAVARD, qui avait repris le volume à Decaux, trouvait ce titre «mauvais »: "C'est un mauvais titre de vente; ça donne comme une arrière-pensée des petits conteurs du XVIII ${ }^{\mathrm{e}}$ siècle, avec un petit air vieillot », cité par L. FORESTIER (Maupassant, 1974, 1495).

6. La nostalgie des sociétés orales - ces mondes perdus - est un topos de la littérature écrite qui évoque volontiers un genre de vie ancien où les rapports sociaux seraient tissés de solidarités franches et de commune, naturelle et plaisante confiance: «Les discours libres et gaillards contenus dans ce petit livre se ressentent encore de l'ancienne prud'homie du bon vieux temps et simplicité de nos pères (...), passant le temps à converser et rire ensemble, auparavant que la naïve bonhomie de leur naturel ne fut corrompue par le malheur des guerres civiles, qui ont chassé par leur division, l'amitié, concorde et privauté, qui ne peut être sans la fiance mutuelle entre les hommes", Guillaume BOUCHET, "Épître à Messieurs les Marchands de la Ville de Poictiers» (1608, non paginé). Voir plus loin, sous la plume de Balzac, une variante moderne et gentry de ce lieu commun littéraire sur les conditions sociales d'énonciation d'une parole libre et franche.

7. «Dans une structure de ce type, la scénographie de l'œuvre n'est ni celle du narrateur extradiégétique, ni celle $\mathrm{du}$ narrateur intra-diégétique mais leur interaction " (Maingueneau, 2004, 198). Sur une approche plus descriptive, voir LINTVELT (1993, 173-185) et sur les types de relations fonctionnelles entre récit(s) encadrant(s) et récit(s) encadré(s), voir GENETTE (1983, 62-63).

8. On se souvient des vers de LA FONTAINE : «Si peau d'âne m'était conté/J'y prendrais un plaisir extrême. » 
9. C'est précisément en comparant les logiques communicationnelles des littératures orales et écrites que le sémioticien observe que « la littérature écrite semble pouvoir être caractérisée par l'intégration, partielle, du code sémantique dans le texte lui-même ». Ce serait d'ailleurs cette absence de code intégré dans son discours (mais codé par toute la situation de contage par exemple) qui rendrait «si difficile » l'analyse de la littérature orale transcrite et réduite à son texte.

10. Sur le plan référentiel, il convient de noter que les bécasses sont effectivement chassées au printemps ou bien à la fin de l'automne. C'est « en hiver que la bécasse a acquis toute sa graisse et qu'elle est recherchée pour la bonté de sa chair » (Belèze, 1867, 198-199).

11. Les histoires de chasse (Hunting Tales) sont classées dans l'Index d'AARNE et THOMPSON (1964) du $\mathrm{n}^{\circ} 1890$ au $\mathrm{n}^{\circ} 1909$, sous-section des contes de mensonges.

12. Voir aussi les réflexions de Walter J. ONG (1973-1974) sur l'entrée progressive dans le monde de la fiction pure et les façons d'engager le lecteur dans la fiction.

13. Les principales revues françaises spécialisées en folklore sont fondées à Paris à cette époque : Mélusine (1877-1878), Revue des traditions populaires (1885), La Tradition (1887).

14. Les lois Ferry sur l'école primaire sont votées en 1881-1882; elles rendent l'école gratuite (1881), l'instruction obligatoire et l'enseignement public laïc (1882).

15. «Le hic et nunc de l'original constitue ce qu'on appelle son authenticité » (Benjamin, 2000a, 71). Le petit auditeur de la lingère... A contrario, le livre (en tant que technique de reproduction) «en multipliant les exemplaires, substitue à une occurrence unique une existence en série » (Benjamin, 2000a, 73).

16. G. DE MAUPASSANT, Clochette, publié dans le Gil Blas du 21 décembre 1886, puis dans le recueil le Horla.

17. L'expérience esthésique de l'unicité et de la fugacité semble au principe de l'expérience auratique (romantique ?) : «Qu'est-ce à vrai dire que l'aura ? (...) Suivre du regard, un après-midi d'été, la ligne d'une chaîne de montagnes à l'horizon, ou une branche qui jette son ombre sur lui, c'est pour l'homme qui se repose, respirer l'aura de ces montagnes ou de cette branche » (Benjamin, 2000a, 75). Il est difficile de ne pas rapprocher ce point de vue et ces exemples de L'Épilogue des Mémoires d'un chasseur (560-561) de TOURGUENIEV : «Que cette forêt est belle (...) aux jours de l'arrière-automne, lors du passage des bécasses. Elles ne tiennent jamais dans le fourré ; c'est toujours près de la lisière qu'on les découvre. Il ne fait point de vent, mais il n'y a non plus ni soleil, ni clarté, ni ombre, ni mouvement, ni bruit; dans l'air léger flotte l'odeur vineuse de l'automne; une brume fine couvre au loin les champs jaunis. Rousses et dénudées, les branches se dessinent sur un ciel immobile et pâle (...). On respire à pleins poumons; et pourtant un trouble étrange vous envahit l'âme. On suit la lisière en surveillant son chien, cependant que des images chères, des figures aimées, mortes ou vivantes, vous reviennent à la mémoire; des impressions endormies depuis longtemps se réveillent à l'improviste; l'imagination prend son vol et plane comme un oiseau; on croit voir surgir toutes ces images (...). Toute votre vie se déroule à vos yeux ». Le récit (oral) du chasseur ne saurait que par abus taxinomique être toujours réduit à un récit de chasse ; parfois, il s'agit d'une première modalité langagière pour donner un aperçu verbal de l'envol de l'imaginaire. Mais en fait, bien plus que le contage traditionnel et ses impératifs de socialité discursive, c'est peut-être bien la littérature écrite (moderne) qui est par excellence le lieu et la formule de cette " rêverie » solitaire et intime, perçue et revécue. On pense à Guillaume APOLLINAIRE («Zone ») : «Tu es dans le jardin d'une auberge aux environs de Prague/Tu te sens tout heureux une rose est sur la table/Et tu observes au lieu d'écrire ton conte en prose/La cétoine qui dort dans le cœur de la rose ». Il y aurait littérature quand il y a méta-littérature.

18. On reconnaît là encore les fameuses thèses benjaminiennes sur «les immenses transformations introduites dans la littérature par l'imprimerie » (Benjamin, 1935, 70). Dans ses « Notices» aux Écrits français, Jean-Maurice MONNOYER fait observer que la «modernisation de 
l'exploitation des hommes est parallèle à l'évolution de l'imprimerie, et celle-ci, dans le feuilletonisme et la littérature de colportage, l'est au déclin de l'art du conte » (Benjamin, 1991, 256). Dans une lettre du 4 juin 1936 adressée à Adorno (AdornoBenjamin, 2006, 161), W. BENJAMIN met lui-même en "parallèle » le fait que «l'art de narrer touche à sa fin » avec le « déclin de l'aura ».

19. La nouvelle de Maupassant est la seconde du recueil de Médan publié sous la haute autorité de Zola. Daniel SANGSUE $(1988,185)$ avait repéré cette parodie qui s'inscrit selon lui dans une série de «manipulations ironiques qui révèlent un Maupassant très lucide sur la définition et l'archéologie du genre qu'il pratique ».

20. Dans une lettre à G. Flaubert (fin avril 1880) qui vient d'encenser Boule de Suif, MAUPASSANT explique qu'il veut «couper court (...) à ces bêtises d'école naturaliste qu'on répète dans les journaux ». Il s'en prend en particulier au titre - Les Soirées de Médan - qu'il a toujours trouvé " mauvais et dangereux ». Il conclut en demandant au maître son avis sur les autres nouvelles du recueil. Il donne le sien, sans détour : «Zola : bien, mais ce sujet aurait pu être traité de la même façon et aussi bien par Mme Sand ou Daudet. Huysmans: pas fameux. Pas de sujet, pas de composition, peu de style. Céard : lourd, très lourd, pas vraisemblable, des tics de style, mais des choses fines et curieuses (...) » (Maupassant par les textes). On peut imaginer qu'avec ses Contes Maupassant défie aussi l'auteur des Trois contes, entre admiration sincère pour Flaubert et affirmation résolue de son style propre. Nous pensons bien sûr à ce récit de chasse tragique qu'est La Légende de saint Julien l'Hospitalier (1877). Maupassant dit à plusieurs reprises son admiration pour ce récit qu'il qualifie de «prodigieux chef-d'œuvre» (le Gaulois, 25 octobre 1881) : un "chef-d'œuvre d'art », un «absolu chef-d'œuvre de couleur et de style » (Maupassant, 1884).

21. Voir, par exemple, Anne GIARD $(1980,13-48)$ et Jean-Marie PRIVAT $(2004,23-52)$.

22. On sait que si MAUPASSANT pouvait apprécier en G. Sand "une grande femme, si simple, géniale et modeste » (le Figaro, 3 juillet 1884), il ne partage ni son esthétique ni son idéologie. Il ironise volontiers sur sa "sentimentalité paysannesque » et sa " passion lyrico-villageoise » (Gil Blas, 6 juillet 1886) ; il dénonce sa manie à se satisfaire d'un « monde gracieux et conventionnel », loin du monde « tel qu'il est » (le Gaulois, 20 juillet 1882).

23. Le Dictionnaire Larousse $d u \mathrm{XIX}^{\mathrm{e}}$ siècle, s.v. «conteur », donne une explication similaire : "Les conteurs, race à peu près disparue depuis l'invention de l'imprimerie et surtout grâce à la multiplicité des gazettes et des journaux (...). C'est à peine si leur trace se retrouve dans les élégants conteurs de salon du siècle dernier (...). Le conteur de village s'est lui-même effacé devant les progrès de la civilisation, et les journaux à un sou l'ont remplacé au coin du foyer animé jadis par ses joyeux récits. »

24. Cité par le Larousse du XIX ${ }^{\mathrm{e}}$ siècle, s.v. « conte ».

25. Selon le Littré, la locution «brider la bécasse » provient d'une chasse qu'on fait aux bécasses avec des lacets et des collets qu'on tend et où les bécasses se brident elles-mêmes et se prennent. La bécasse a toutefois la réputation d'être discrète, rusée et méfiante, aussi difficile à chasser... que délicieuse à consommer.

26. En cuisine (Favre, 1905, 253), on utilise généralement les têtes de bécasse pour former des attelets (petite brochette) : «On peut facilement, lorsque la saison du gibier commence, en faire préparer, en ayant soin de faire enfoncer une brochette de métal dans la tête afin de pouvoir la fixer. On laisse le bec en l'air pour le garnir de truffes, de crêtes ou de champignons. On peut aussi piquer le bec sur le croûton et laisser la tête en haut ».

27. "Maupassant cite Boccace avec admiration dans ses chroniques. Le Décaméron et les Cent nouvelles nouvelles ont été reconnus comme des hypo-textes des contes maupassantiens : même structure reposant sur l'oralité, mêmes thèmes. L'écrivain normand participa à chaque volume $\mathrm{du}$ Nouveau Décaméron, publié chez Dentu en 1885, hommage au célèbre Toscan » (Benhamou, 2006, 133-149). 
28. Le lien entre chasse, propos de table et érotisme est comme on sait très souvent explicite chez MAUPASSANT : "C'était la fin du dîner d'ouverture de chasse chez le marquis de Bertrans. Onze chasseurs, huit jeunes femmes étaient assis autour de la grande table illuminée, couverte de fruits et de fleurs. On en vint à parler d'amour». («la Rempailleuse», le Gaulois, 17 septembre 1882). Ici l'homologie discursive entre «aiguille », «bec » et " nez » introduit en son temps à un discret imaginaire onirique (artefact/animal/humain) et nous fait songer aujourd'hui à l'univers anthropologique et artistique des masques exotiques étudiés par Cl. LÉVISTRAUSS $(1979,16-18)$, masques cérémoniels ornés de têtes d'oiseaux et où « le nez, pointu et recourbé », évoque précisément « un bec d'oiseau ». Dans les potlatchs décrits par l'ethnologue, il est aussi question de gigantesques plats cérémoniels qui, par rapport aux invités assis selon leur rang, doivent s'immobiliser dans la position correcte, « derrière le foyer, la tête pointée vers le poteau central situé au fond de la maison (...). Un intendant dirigeait les opérations, décidant et annonçant le nombre de plats assignés à chaque groupe de convives »... (1979, 81-84).

29. Le Dictionnaire de l'Académie française (éd. 1762) propose cette définition : « Le roi boit. Sorte de cri de réjouissance parmi ceux qui mangent ensemble le jour des Rois, après avoir fait un Roi de la fève. On crie, Le Roi boit, Toutes les fois que le Roi de la fève boit. Quand c'est une Dame qui est la Reine de la fève, on crie, La Reine boit ». Il était d'usage que ceux qui manquaient de crier le Roi-boit étaient « condamnés à être barbouillés » (Van Gennep, 1988, 3531-3585).

30. mAUPASSANt (1887) lie explicitement les codes cynégétiques et sexuels - sur fond de plaisanterie graveleuse ( tirer une bécasse »)... et de réflexion sur les passions humaines pour la quête sauvage: «La chasse! Quel est l'homme qui ferait pour une femme ou des femmes, durant toute sa vie, ce qu'un chasseur fait pour la chasse? Songez aux voyages en carriole, par les nuits froides, pour aller tuer quelques lapins, aux autres nuits passées dans les marais, sous une hutte de paille ou de glace, aux pluies battantes reçues pendant des saisons entières, aux prodigieuses fatigues, aux mauvais repas des fermes, aux marches interminables. Est-il un amoureux qui supporterait cela pour sa maîtresse? Est-il un joueur qui affronterait ces fatigues et ces privations pour aller tenir une banque au fond d'un bois ? Est-il un ivrogne qui ferait vingt lieues sous la grêle pour boire un verre de fine champagne, comme le fait un chasseur pour tirer une bécasse? - Alors? Alors? Alors?».

31. L'intertexte littéraire de la fête des Rois est évidemment très présent au XIX siècle, de NotreDame de Paris - « le 6 janvier (...), double solennité, depuis un temps immémorial, du jour des Rois et de la Fête des Fous " - à Madame Bovary - le père Rouault «s'était cassé la jambe, la veille au soir, en revenant de faire les Rois, chez un voisin ». On se souvient que c'est cet accident qui provoquera dans la fiction la rencontre à la ferme des Bertaux du jeune médecin Charles Bovary et de Mademoiselle Emma Rouault.

32. Ici ou là " les conscrits doivent faucher le coq enterré avec une faux emmanchée à l'envers » (Van Gennep, 1949, 959). Le vainqueur - le Roi des Coqs... - est proclamé Roi de la Jeunesse. Le plus souvent l'oie était décapitée selon les mêmes règles coutumières (culture de garçon, violence rituelle et publique, bestiaire domestique, geste en aveugle, redevance, couronnement folklorique, partage du festin). La littérature ethnographique sur le sujet est très importante. Je remercie Marie Scarpa d'avoir attiré mon attention sur ce point capital.

33. Il en allait pareillement pour le jeu du tir au "papegault» organisé par les compagnies d'archers et d'arbalétriers. On fixait au sommet d'une perche un tout petit oiseau, un papegault. Le vainqueur du tournoi, recevait le titre de "Roy» et jouissait pour un temps de certains privilèges. Gargantua tirait au « papegay » (Van Gennep, 1947, 1102). Le fait de couper dans le vif ou de trancher le col par exemple était un geste que faisait et qui faisait l'homme (Méchin, 1992). Ainsi, dans les rites agricoles cette fois, « la dernière gerbe » était-elle censée contenir « un coq vivant». Le faucilleur arrivé premier avait «le droit de couper cette gerbe et devait ensuite trancher d'un coup de faucille la tête de ce coq réel qu'on mangeait au festin de terminaison ». (Van Gennep, 1951, 2266). 
34. Selon A. DUMAS, friand d'anecdotes sur la bécasse, « on vénère tellement ce précieux oiseau, qu'on lui rend les mêmes honneurs qu'au grand lama : des rôties mouillées d'un bon jus de citron reçoivent ses déjections, et sont mangées avec respect par les fervents amateurs (...). Autrefois, quand les dieux descendaient sur la terre, ils ne se nourrissaient pas autrement » (Dumas et Vuillemot, 1873, 213).

35. Je cite les textes bibliques d'après la traduction de LEMAîTRE DE SACY, traduction de référence pour le $\mathrm{XIX}^{\mathrm{e}}$ siècle. On lit aussi, toujours dans le Lévitique, 4.26 par exemple, à propos du grand prêtre sacrificateur: "Il brûlera toute la graisse sur l'autel, comme la graisse du sacrifice d'actions de grâces». Ailleurs il est question "d'offrir en sacrifice deux tourterelles ou deux jeunes pigeons, comme cela est prescrit dans la loi du Seigneur », (Luc, 2.24).

36. On connaît les grandes lignes du fameux épisode: "Tout le peuple s'assit pour manger et pour boire, et ils se levèrent ensuite pour jouer (...). Le lendemain Moïse dit au peuple : - Vous avez commis un très grand péché (...). Et étant retourné vers le Seigneur, il lui dit : - Ils se sont fait des dieux d'or (...). Le Seigneur lui répondit: - J'effacerai de mon livre celui qui aura péché contre moi », (Exode, XxxII, 6, et XXXII, 30-33).

37. Sur une approche sémiotique stricte de "l'isotopie à la fois profondément chrétienne et sacrilège » des Deux amis de Maupassant, voir Greimas (1976b, 259-261. Ici, le recueil lui-même inclut un conte intitulé Le Testament (1882) où il est question dans le discours du narrateur de très « antiques usages» ou de « lois surannées » et dans la bouche du personnage principal de «Juge suprême », de " malédiction du ciel » et de « coutumes inhumaines ».

38. Le saint chrême (en grec chrisma, " onguent », " huile », d'où « onction ») est la principale des saintes huiles consacrées par l'évêque lors de la messe chrismale, le Jeudi saint au matin (voir aussi Bonnefis, 2009, 34-37 et 42-44).

39. La parodia sacra est la parodie des textes et rites sacrés; la parodia sacra de la Cène en est peut-être l'exemple paradigmatique.

40. On pourrait même lire dans cette scène en clair-obscur (chandelle allumée, attente muette et anxieuse, fumée sacrificielle) une esquisse subliminale de retournement bouffon de la Crucifixion : tête ointe, crâne fixé sur une épingle, petits bâtons croisés. Sur le folklore religieux lié à la bécasse et à son bec qui effaçait les traces laissées par la Sainte Famille lors de la fuite en Égypte (Sébillot, 1968, 171).

41. On dirait que l'écrivain imagine un mât de cocagne cérémoniel et domestique : « Les Eskimos d'Asie ont inventé une sorte de mécanique, une roue ornée de toutes sortes de provisions, et portée sur une espèce de mât de cocagne surmonté lui-même d'une tête de morse. Cette partie du mât dépasse la tente de cérémonie dont il forme l'axe. Il est manœuvré à l'intérieur de la tente à l'aide d'une autre roue et on le fait tourner dans le sens du mouvement du soleil» (Mauss, 2010, 93).

42. Le suif est un corps gras et consistant fourni par les ruminants. Il sert à faire les chandelles.

43. Les jeux et spécialement les jeux de hasard sont généralement condamnés par les religions comme attentatoires au plan divin. Dans les Évangiles, les soldats jouent aux dés la tunique du Christ: "Après l'avoir crucifié, ils se partagèrent ses vêtements, en tirant au sort, afin que s'accomplît ce qui avait été annoncé par le prophète : Ils se sont partagé mes vêtements, et ils ont tiré au sort ma tunique ». (Matthieu, 27,35). Cette scène est un motif de la peinture religieuse occidentale et du théâtre médiéval (le théâtre des mystères comme le théâtre de la farce carnavalesque).

44. Voir aussi Matthieu, 14,1-13 où il est question de retour du mort (« C'est Jean-Baptiste qui est ressuscité d'entre les morts »,14,2), de femme interdite ( Il ne vous est point permis d'avoir cette femme»,14,4), de festin rituel («La fille d'Hérodiade dansa devant tous les conviés ", 14,6), de don royal ("Il lui promit avec serment de lui donner tout ce qu'elle lui demanderait », 6-7) et de contre-don («Donnez-moi présentement dans un bassin la tête de Jean- 
Baptiste », 6, 8), enfin de multiplications des pains ("Jésus ayant appris ce qu'Hérode disait de lui, il partit de là dans une barque », 6, 13).

45. Le XIX ${ }^{\mathrm{e}}$ siècle est le grand siècle musical, pictural et littéraire du mythe de Salomé.

46. La préparation culinaire et la consommation gourmande de la bécasse présentent quelque chose de violent, tant sur le plan symbolique (vocabulaire) que sur le plan des plaisirs de bouche : « La bécasse exige d'être légèrement mortifiée. On ne la vide pas. On traverse son corps avec son bec. On la barde et on la fait rôtir à feu vif (...) avec des tranches de pain dessous » (Dubois, 1889, 317-318).

47. L'isotopie politique et sanglante de la décapitation révolutionnaire (la tête du roi au bout d'une pique et les têtes piquées sur une tête d'épingle) est aussi clairement présente à fleur de texte (le vieux baron, le roi des chasseurs, le siècle dernier, l'ancien temps, la reine des gibiers, etc.).

48. Pour exemple biblique : «Demandez à l'Éternel la pluie, la pluie du printemps ! L'Éternel produira des éclairs, Et il vous enverra une abondante pluie, Il donnera à chacun de l'herbe dans son champ ", (Zacharie, 10.1).

49. Cette fascination pour les plaisirs charnels liés à la consommation des bécasses se lit aperto libro dans le fameux Dictionnaire universel de cuisine pratique de FAVRE (1905, 248-253) : «La bécasse, cette reine des marais, est un gibier à chair noire ; lorsqu'elle est grasse et jeune, elle est classée au premier rang d'excellence (...). On barde les bécasses, on les bride, en transperçant de leur bec, les cuisses, le corps et le lard (...). La bécasse, par son fumet délicieux, par la succulence de sa chair, figure au rang des gibiers à plumes les plus fins, les plus distingués (...). La chair de la bécasse est très agréable, stimulante, et partant aphrodisiaque ». L'encyclopédiste ne se prive même pas d'une allusion mondaine et coquine en citant ces vers de mirliton : "On sert aux poètes et aux gourmets/Ainsi qu'aux b... coiffées/Le plus délicieux des mets/Qui donne aux femmes la tendresse/Aux yeux l'éclat, au cœur bonté/Et aux tireurs de Tell l'adresse/Énergie et virilité ».

50. On est évidemment dans l'ordre mondain de la chair gourmande (l'isotopie sexuelle affleure en permanence dans un texte qui parle de coups de fusils et de culbute) et non dans l'ordre mystique de la charité évangélique : «Lorsque tu donnes à dîner ou à souper, n'invite pas tes amis, ni tes frères, ni tes parents, ni des voisins riches, de peur qu'ils ne t'invitent à leur tour et qu'on ne te rende la pareille. Mais, lorsque tu donnes un festin, invite des pauvres, des estropiés, des boiteux, des aveugles. Et tu seras heureux de ce qu'ils ne peuvent pas te rendre la pareille; car elle te sera rendue à la résurrection des justes ", (Luc, 14, 12-14).

51. Theuth, le héros mythique dont parle PLATON à propos de l'invention de l'écriture (Phèdre, 274d) est souvent représenté de profil avec un calame à la main et un très long bec d'oiseau ibis.

52. L'essayiste ajoute: «Le lecteur de roman, lui, est solitaire. Il l'est plus que tout autre lecteur ».

53. On retrouverait ici les analyses de Roland BARTHEs (1970, 95-96) qui parle du Récit comme «monnaie d'échange, objet de contrat, enjeu économique, en un mot marchandise (...) dont la transaction (...) se représente elle-même dans la narration?» Et pose la question générique : "Contre quoi s'échange le récit? Que "vaut" le récit?".

54. Selon Charles CASTELla $(2000,114)$, les Contes de la bécasse dans leur ensemble reposent sur une logique de la dette, la compensation étant en quelque façon la structure génétique (et malheureuse) de ces récits. La Bécasse en serait la microstructure révélatrice.

55. Le récit de «la Folle» fut publié dans le Gaulois du 5 décembre 1882, puis inséré dans le recueil des Contes de la bécasse. Un autre conte plus tardif - intitulé les Bécasses cette fois - tresse à son tour les thèmes du malheur brutal, de la sombre folie et de la mort violente (Maupassant, 1979, 563-571). Cette histoire s'offre comme un piège, un miroir aux alouettes. Son titre n'est en rien programmatique de son contenu et brouille les pistes comme à plaisir. En effet, 
au moment du passage des bécasses les chasseurs préfèrent chasser... le lapin : « Nous sommes convaincus qu'il ne faut pas chercher la bécasse, mais la trouver. On tombe dessus et on la tue, voilà. Quand on veut spécialement en rencontrer, on ne les pince jamais (...). Quand j'ai tué une bécasse, je crie: “Lapin!”Et je triomphe avec excès lorsqu'on sort les pièces du carnier, au déjeuner de midi ». Gare aux lecteurs!

56. Ce motif de la perte est topique dans la culture occidentale. Un exemple suffira pour illustrer ce malaise dans la communication/communion : «Quoique j'eusse beaucoup choses à vous écrire, je n'ai pas voulu le faire avec le papier et l'encre ; mais j'espère aller chez vous, et vous parler de bouche à bouche, afin que notre joie soit parfaite ». (Épître de l'apôtre Jean, 2.1.12). Le lien de l'oralité conteuse plus forte que la mort est évidemment le motif même du jeu de don (la fable) et de contre-don (la vie) qui structure le scénario des Mille et Une Nuits. Évoquer la figure de Schéhérazade à l'horizon de son écriture ne déplaît d'ailleurs pas à Maupassant: "C'était pendant la saison des chasses, dans le château de Banneville. L'automne était pluvieux et triste (...). Le vent faisait sur les volets des poussées bruyantes et lançait les vieilles girouettes en des tournoiements de toupie. On voulut alors conter des histoires, comme il est dit en des livres ; mais personne n'inventait rien d'amusant. Les chasseurs narraient des aventures à coups de fusil, des boucheries de lapins; et les femmes se creusaient la tête sans y découvrir jamais l'imagination de Schéhérazade ». (Une Veuve, le Gaulois, $1^{\mathrm{er}}$ septembre 1882).

57. Sur le passage du savoir par les oiseaux au savoir par la lettre, voir les analyses de Daniel Fabre (1986, 7-40).

\section{RÉSUMÉS}

L'étude porte sur la Bécasse, texte d'ouverture des "Contes de la bécasse » de Maupassant. Ce court récit rapporte comment la parole conteuse est déléguée à des invités réunis coutumièrement autour d'une bonne table. L'analyse souligne la recherche d'effets d'oralité traditionnelle (langages, partage de la performance verbale, motifs, structures discursives) dans une littérature écrite moderne marquée par la nostalgie culturelle d'un monde où les voix amicales et lettrées ne seraient plus que des voix de papier. Conformément au pacte de l'écriture réaliste, le récit réécrit et parodie d'autres univers selon la logique des imaginaires carnavalesques. L'étude montre enfin et surtout comment la dynamique narrative et les échanges symboliques sont organisés ici selon la logique maussienne du don et de la réciprocité. Comme si l'utopie de cette littérature était d'être à la fois l'écriture d'un rite et un rite de l'écrit.

This paper is about la Bécasse, the opening text of the "Contes de la bécasse" by Maupassant. This short story relates how different guests, gathered regularly for meal, share the role of the storytelling. This paper underlines the effects of traditional orality (speeches, sharing of the performance, motifs, discursive structures) in a form of modern written literature characterized by a cultural nostalgia for a world where friendly and literate voices have been reduced to mere paper voices. In accordance with the reading pact of realism, the tale re-writes and parodies other worlds, following the imaginary structure of carnival. Finally, this paper shows how the narrative dynamics and the symbolic exchanges are organized on Mauss' model of gift and reciprocity. As if the utopic dream of such a literature were to be both, and at the same time a ritual writing and a writing ritual. 
INDEX

Mots-clés : Maupassant Guy de (1850-1893), la Bécasse, récit-cadre, institutions de transfert, rite, intertextualité, effet d'oralité, aura, logique de don, nostalgie culturelle, salut littéraire Keywords : Maupassant Guy de (1882), la Bécasse, Frame Narrative, Institutions of Transfer, Ritual, Intertextuality, Orality Effect, Aura, Gift, Cultural Nostalgia, Salvation of Literature

Thèmes : anthropologie (Europe), littérature orale

\section{AUTEUR}

JEAN-MARIE PRIVAT

CREM, Université de Lorraine 